\section{Cinderella indications for compression therapy}

\section{Giovanni Mosti, ${ }^{1}$ Hugo Partsch ${ }^{2}$ \\ 'Angiology Department, Barbantini Clinic, Lucca, Italy; ${ }^{2}$ Department of Dermatology and Angiology, Medical University of Vienna, Vienna, Austria}

Cinderella is the poor, underestimated girl in the fairy tale whose beauty stays unrecognized till the time when a clever prince discovers her.

There are many indications for compression therapy outside the phlebo-lymhological area. They are also forgotten, underestimated and unrecognized but deserve to be newly discovered. This may also shed light on our principle to understand the mechanisms of action and exceed our conventional hemodynamic ideas about how compression works.

The tradition of compression, which is one of the oldest management procedures in medicine, dates back thousands of years and is obviously based on the experience that applying pressure to a painful part of the body helps in relieving symptoms. Already prehistoric rock paintings show the simplest form of compressive hands but also of bandages applied to the extremities, obviously used after trauma and bleeding. ${ }^{1}$ This demonstrates that traumatic lesions were much more frequent and important for the ancient healers than our present phlebo-lymphological indications.

The present issue basically contains the collection of extended abstracts presented at the Annual Scientific Meeting of the International Compression Club (ICC), held in Bari (Italy) on October 2015.

The first three presentations deal with the effects of compression on inflammatory symptoms. After a general introduction by Ligi $e t$ $a l .,{ }^{2}$ Valentina Dini reports her positive experience in treatment of different kind of vasculitis by compression therapy. ${ }^{3}$ Alberto Macciò underlines the anti-inflammatory effect of compression in dermato-lymphangio-adenits commonly named erysipelas or cellulitis. This condition is usually considered a contraindication for compression, while with his presentation Alberto Macciò demonstrates that, thoroughly applied zinc paste, bandages are very effective in reducing inflammation and painful swelling. ${ }^{4}$ Mieke Flour presents a series of completely unusual indications both on polytrauma patients and endocrinopaties including myxedema and diabetes mellitus. ${ }^{5}$

Again, Flour et al. ${ }^{6}$ present interesting data on another very unusual indication represented by burns and scars.

Venous leg ulcers are the classical indication for compression treatment. Less known is the fact that wounds of the leg due to other pathologies respond also quite nicely to good compression. This is shown by Enzo Fracchia ${ }^{7}$ for hematological ulcers, by Giovanni Mosti, ${ }^{8}$ for mixed, arterial-venous ulcers, by Patricia Senet, ${ }^{9}$ for the hypertensive ulcer and by Rolf Jelnes, ${ }^{10}$ for posttraumatic ulcers.

Oscar Maleti refers his positive experience in applying compression to the leg after venous hervesting for aorto-coronary by-pass. ${ }^{11}$

Brorson et al., ${ }^{12}$ pioneer in reducing lymphoedema by liposuction show in their very practice-orientated presentation that additional compression is indispensable before and after surgery.

Hugo Partsch emphasizes the importance of compression therapy in deep vein thrombosis and in prevention of post-thrombotic syndrome despite of some recent papers with negative report on this topic. ${ }^{13}$

Compression seems to have positive effects also in healthy people practicing sports. These aspects are underlined in the paragraphs by Jean Patrick Benigni ${ }^{14}$ and Helmut Lötzerich. ${ }^{15}$

Finally, Bender and co-authors present interesting data on a completely obscure indication for compression represented by the restless leg syndrome. ${ }^{16}$ It seems very clear from all the following reports that what was considered a Cinderella indication or even a contraindication for compression therapy is actually a true indication.

\section{References}

1. Gardon-Mollard C. 10.000 years of history of medical support bandaging. Paris: Elsevier Masson; 2011.

2. Ligi D, Croce L, Mannello F. Inflammation and compression: the state of art. Veins and Lymphatics 2016;5:5980.

3. Dini V. Compression in vasculitis. Veins and Lymphatics 2016;5:5981.

4. Macciò A. Compression in dermato-lym-
Correspondence: Giovanni Mosti, Angiology Department, Barbantini Clinic, via del Calcio, 55100 Lucca, Italy.

E-mail: giovanni.mosti10@gmail.com

This work is licensed under a Creative Commons Attribution 4.0 License (by-nc 4.0).

(C) Copyright G. Mosti, 2016

Licensee PAGEPress, Italy

Veins and Lymphatics 2016; 5:5979

doi:10.4081/vl.2016.5979

phangio-adenits. Veins and Lymphatics 2016;5:5982.

5. Flour M. Compression treatment following polytrauma and in endocrinopathies. Veins and Lymphatics 2016;5:5983.

6. Flour M, Anthonissen M, Van den Kerckhove E. Pressure therapy for postburn scars: does it work? Veins and Lymphatics 2016;5:5984.

7. Fracchia E, Cantello C, Gori A, et al. Ulcers in congenital anemia. Veins and Lymphatics 2016;5:5985.

8. Mosti G. Compression in mixed ulcers. Veins and Lymphatics 2016;5:5986.

9. Senet P. Compression in hypertensive leg ulcer (Martorell's ulcer). Veins and Lymphatics 2016;5:5987.

10. Jelnes R. Compression after trauma. Veins and Lymphatics 2016;5:5988.

11. Maleti 0 . Compression after vein harvesting for coronary bypass. Veins and Lymphatics 2016;5:5989.

12. Brorson H, Svensson B, Ohlin K. Role of compression after liposuction. Veins and Lymphatics 2016;5:5990.

13. Partsch H. Compression and deep vein thrombosis. Veins and Lymphatics 2016;5:5991.

14. Benigni JP. Compression and sports. Veins and Lymphatics 2016;5:5992.

15. Lötzerich H. Effects of compression on performance and regeneration. Veins and Lymphatics 2016;5:5993.

16. Bender D, Kuhn PJ, Olson DJ, Sullivan JP. Adjustable topical compression foot wrap, is more effective than a dopamine agonist, ropinirole, in reducing the symptoms of moderate to severe restless leg syndrome. Veins and Lymphatics 2016;5:5994. 